Financial support was given by the Medical Research Council and the Haemophilia Society.

Our preliminary findings were reported by K.M.D. to the Institute of Haemophilia during the 10th World Congress of the International Society for the Rehabilitation of the Disabled, Wiesbaden, September 1966.

REFERENCES

Ahlberg, А. (1965). Acta orthop. scand., Suppl. No. 77, p. 74.

Bennett, E., Dormandy, K. M., Churchill, W. G. L., Coward, A. R., Smith, M., and Cleghorn, T. E. (1967). Brit. med. f., 2, 88

Biggs, R. (1964). Proc. roy. Soc. Med., 57, 1171.

and Matthews, J. M. (1966). Treatment of Haemophilia and Other Coagulation Disorders, edited by R. Biggs and R. G. Macfarlane, p. 129 . Oxford.

Brit. med. f., 1966, 2, 1608.

Brinkhuus, K. M., Swanton, M., Webster, W. P., and Roberts, H. R. (1966). Proceedings of Congress of the World Federation of Hemophilia, Australia. In press.

Britten, M. I., Spooner, R. J. D., Dormandy, K. M., and Biggs, R. (1966). Brit. med. F., 2, 224.
Dalrymple-Champneys, W., Hunter, J. R., and Polton, K. R. (1967). Ibid., 2, 440.

DePalma, A. F., and Cotler, J. (1956). Clin. Orthop., 8, 163.

Evans, E. S. (1967). Proceedings of British Orthopaedic Association Clinical Meeting, Spring, 1967, p. 54.

France, W. G., and Wolf, P.'(1965). f. Bone ft Surg., 47B, 247.

Hardisty, R. M., and Ingram, G. I. C. (1965). Bleeding Disorders : Investigation and Management, p. 78 . Oxford.

Jordan, H. H. (1965a). Acta orthop. belg., 31, 640.

- (1965b). Proceedings of Institutes on Hemophilia (National Hemophilia Foundation, N.Y.), p. 22.

Matthews, J. M. (1966). Treatment of Haemophilia and other Coagulation 'Disorders, edited by R. Biggs and R. G. Macfarlane, p. 70. Oxford.

Poulain, P. (1964). Réadaptation, No. 108, p. 27.

Ramgren, O. (1962). Acta med. scand., 171, 237.

Salzman, E. W., and Britten, A. (1965). Hemorrhage and Thrombosis, p. 38. Boston and London:

Stuart, J., Davies, S. H., Cumming, R. A., Girdwood, R. H., and Darg, A. (1906). Brit. med. ₹., 2, 1624.

van Creveld, S. (1964). Nederlandse Hemofiliestichting, p. 2. Utrecht.

Wilkinson, J. F., Nour-Eldin, F., Israëls, M. C. G., and Barrett, K. E. (1961). Lancet, 2, 947.

\title{
Trial of Gastric Cooling for Haematemesis*
}

\author{
J. B. McFARLAND, $\dagger$ M.D., CH.M., F.R.C.S. ; J. G. GOW, $\ddagger$ M.D., CH.M., F.R.C.S.
}

Brit. med. F., 1967, 3, 831-834

Gastric cooling as a method of controlling upper gastrointestinal haemorrhage was initially developed by Wangensteen et al. (1958). The temperature and the rate of flow of coolant which they employed produced an intragastric temperature of the order of $15^{\circ} \mathrm{C}$. They suggested that this caused: (1) reduced gastric blood flow; (2) depressed acid/pepsin secretion and activity ; and (3) decreased gastric motility.

In an extended clinical series they reported on the treatment of 75 patients by gastric cooling, with control of haemorrhage in $57(76 \%$ ) (Nicoloff et al., 1962). This result is comparable to the figures analysed by Crampton et al. (1964), who added a further 123 reported cases and noted an overall control of haemorrhage in $72.6 \%$. Unfortunately, cessation of haemorrhage cannot necessarily be equated with patients' survival, and in one of the large series included in this analysis (Wangensteen et al., 1963) haemorrhage was controlled in $87 \%$ of cases but the hospital mortality was $57 \%$.

Usually a commercial refrigerator formed the basis of the apparatus for gastric cooling. A refrigerated alcohol/water solution was pumped through an intragastric balloon. Mechanical complications with such apparatus have been described by Wangensteen (1962), Nicoloff et al. (1962), Richman and Anthony (1963), and Miller et al. (1963). Because of these complications a simplified water-circulating apparatus was used in this study.

Haematemesis is an alarming symptom of a serious situation. There is a definite place for a non-operative technique that would assist in its early management and allow time for an exact diagnosis to be made later. We here compare a trial of early gastric cooling with conventional methods of managing massive gastrointestinal haemorrhage.

\section{Subjects, Materials, and Methods}

The patients treated had been admitted urgently to a general hospital after a haematemesis or melaena. The condition was thought to be serious enough for the subject to be included in the series if one or more of the following features were

* From a paper read at the Annual Meeting of the British Society of Gastroenterology held in London on 3-5 November 1966.

$\dagger$ Senior Lecturer in Surgery, University of Liverpool.
: Consultant Surgeon, Liverpool Regional Hospital Board present: (1) haematemesis in excess of $1,000 \mathrm{ml}$., observed by a competent medical witness ; (2) fall in systolic blood pressure to $100 \mathrm{~mm}$. $\mathrm{Hg}$. or below for one hour or longer ; and (3) acute fall in haemoglobin to below $10.2 \mathrm{~g} . / 100 \mathrm{ml}$. or haematocrit to below 30\%.

The patient was admitted to a special unit in a surgical ward, and after he had been assigned to an age group (under or over 50 years) a random selection was made for treatment to include gastric cooling or to be by conventional methods.

The policy of the conservative management is indicated by the following points:

(1) Blood was replaced intravenously at a rate and to an amount indicated by the patient's condition. The blood pressure, pulse rate, haemoglobin, and haematocrit were used as guides, though less importance was given to the latter two in the later stages.

(2) Intravenous dextrose/saline was given slowly $(500 \mathrm{ml}$. sixhourly), usually to keep an intravenous drip infusion open.

(3) A nasogastric tube was not used during conservative management and was introduced only if operation (or gastric cooling) was planned.

(4) The patient was encouraged to take milk-and-water orally during conservative management (and immediately after a period of gastric cooling).

(5) Sedation, usually by intramuscular injection, was used as indicated. The drug used was decided for each patient individually: morphine, Omnopon, and a combination of chlorpromazine 25 mg. with promethazine $25 \mathrm{mg}$. were most commonly given.

(6) Antibiotics, usually by injection, were given when specifically indicated or when cover appeared particularly valuable.

Half the patients in the series were managed conservatively. For the other half gastric cooling was used in addition.

A few days subsequent to this treatment a barium-meal or Gastrografin $x$-ray examination was carried out.

\section{Gastric Cooling Apparatus}

The cooling unit in this study was the Cryocycle hypothermia system (Fig. 1). This consisted, in principle, of a pump which circulated water at a rate of about 2 litres a minute in a closed system through copper pipes in an ice-bath, and by tubes to the intragastric balloon. A double balloon of extremely thin (condom) rubber was used with a thermistor 
lying between the balloons. The cooled water entered through the centre of the coaxial tube, was ejected laterally into the balloon, and returned through the outer tube.

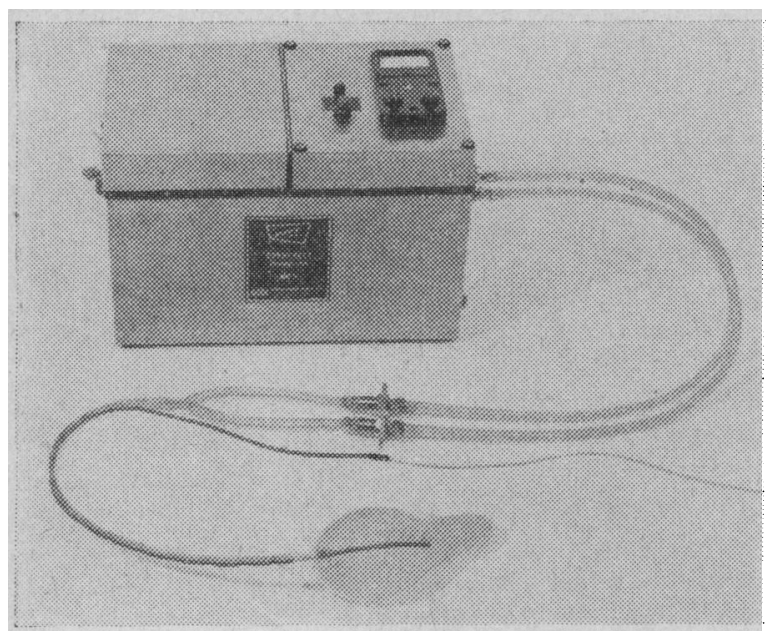

FIG. 1.-Photograph of the Cryocycle hypothermia system. A thermistor lies between the two thin walls of the double balloon, which has been filled with $800 \mathrm{ml}$. of water.

\section{Technique of Gastric Cooling}

When the decision to employ gastric cooling had been made the patient was usually sedated with promethazine $25 \mathrm{mg}$. and chlorpromazine $25 \mathrm{mg}$., given intramuscularly. A local anaesthetic spray of $4 \%$ lignocaine was used to numb the patient's throat. A nasogastric tube was passed and the patient's stomach was thoroughly lavaged with cold water.

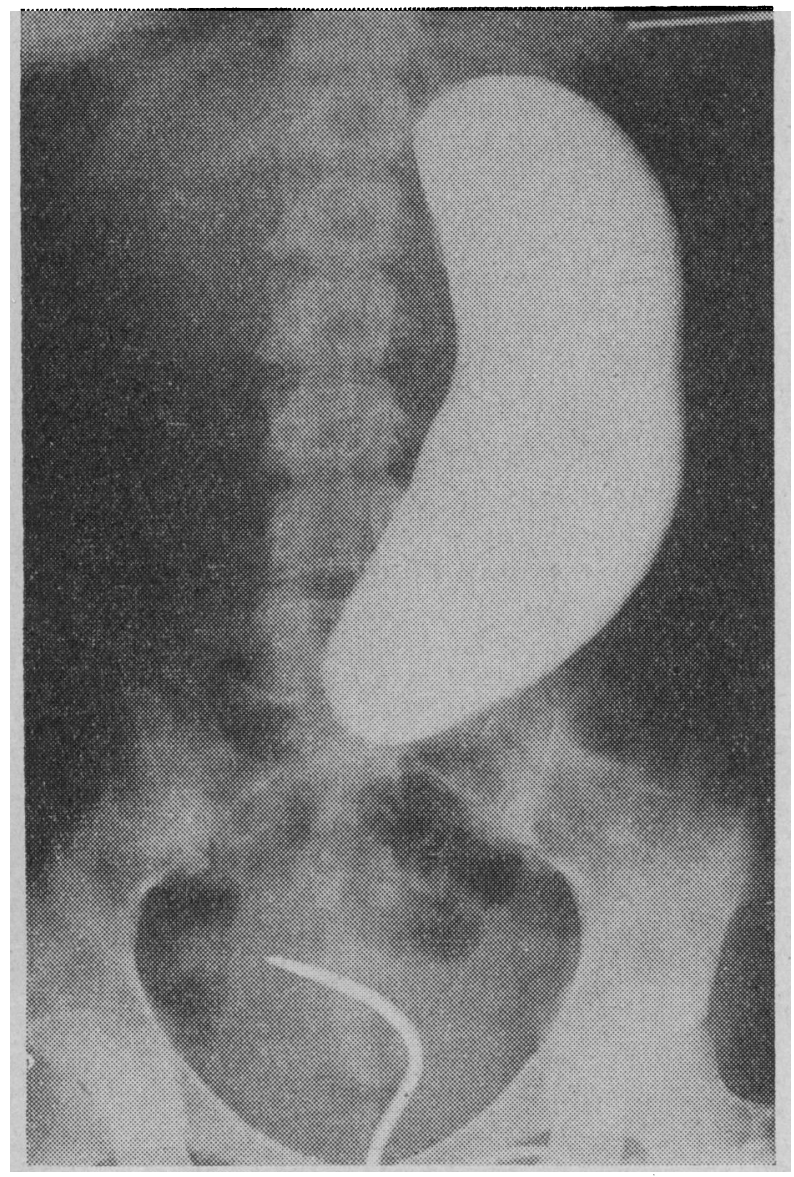

FIG. 2.-Radiograph showing a balloon filled with radio-opaque fuid in a normal stomach. Part of the thermistor lead may be seen in the stomach. The lower thermistor is in the
This was continued right up to the time for the gastric cooling balloon to be passed, when the nasogastric tube was withdrawn. Every effort was made to empty the stomach completely, especially to remove all blood clot and thus allow good contact between the balloon and the mucosa.

The length of the tube to be passed was gauged roughly against the patient, and the tube was then slowly but steadily introduced. It was most important to have the suction ready for immediate use from this point and to aspirate any regurgitated mucus or blood. The passage of the balloon was usually not difficult, but was of course easier in edentulous subjects. With the balloon and the tubes in position they were filled with $800 \mathrm{ml}$. of water in $50-\mathrm{ml}$. increments from a special syringe.

As a routine the position of the balloon was checked by one straight radiograph of the abdomen shortly after the beginning of treatment. The thermistor lead served as a guide to the position of the balloon. If more accurate visualization of the balloon was required a radio-opaque solution, such as Hypaque, could be introduced into it. Fig. 2 shows the $x$-ray plate obtained in this way from a normal-sized stomach.

When the gastric cooling was under way the pump circulated the water through the closed system of the tubes, the balloon, and the pipes in the bath. Supervision of the hypothermia machine required only that the bath was maintained with water and ice to a level covering the pipes. Carbon dioxide ice ("dry ice") was added as a "booster"; this was not essential, but it conserved the amount of ice used (over $1 \mathrm{cwt} .(50.8 \mathrm{~kg}$.) in 24 hours).

During the period of gastric cooling the intragastric, rectal, bath, inflow, and outflow temperatures were monitored (Fig. 3). Pulse rate, blood pressure, and respiration were recorded hourly ; electrocardiography was carried out; haemoglobin and haematocrit estimations were done at regular intervals; the

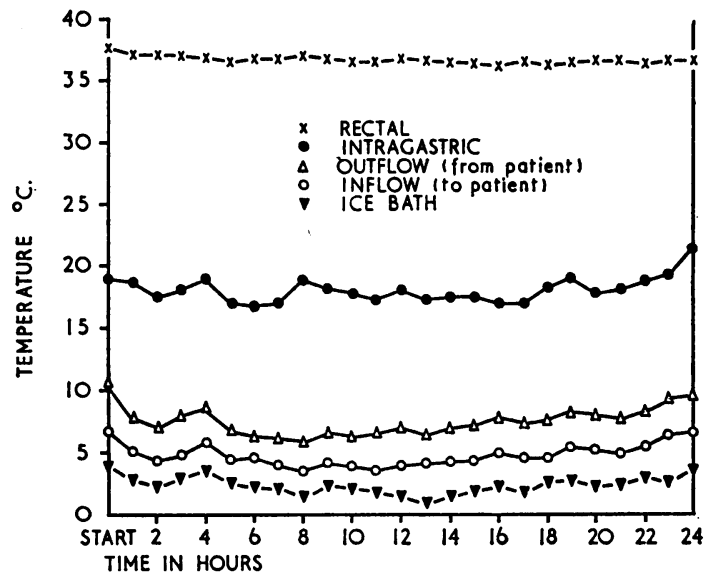

FIG. 3-Graph of the temperatures during gastric cooling. This was compiled by averaging the figures for 10 cases early in the series.

bleeding- and clotting-times were measured once; and the blood urea and electrolytes were estimated daily. Urine volume was recorded, checks being made on specific gravity and urea concentration.

In almost all cases gastric cooling was continued for 24 hours. Soon after it was under way the patient was covered by an electric blanket (in addition to ordinary blankets), and this was switched on as soon as any shivering or tendency of the rectal temperature to fall was noted. The level of external warming was aimed at limiting the fall in rectal temperature to only a few degrees, and sometimes a second electric blanket was required. At the completion of the period of gastric cooling the pump was switched off and the intragastric temperature allowed to level out with the body temperature. The balloon was emptied and removed. 


\section{Results}

This paper describes the outcome in 44 patients treated within a two-year period. The apparent causes of the haemorrhage in this series are indicated in Table I.

Table II gives the overall outcome in the broad terms of complete recovery, successful operation, or death in each group. All hospital deaths are shown, and these are further summarized in Table III.

Table IV indicates the degree of success or failure of arrest of haemorrhage (indicated by absence of melaena, clear gastric

TABIE I.-Haematemesis: Diagnosis in 44 Cases

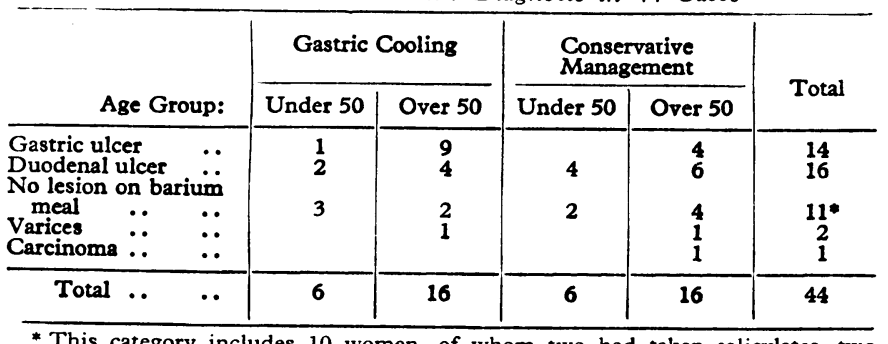

* This category includes 10 women, of whom two had taken salicylates, two were on corticosteroid therapy, and six remained undiagnosed. The one man had

TABLE II.-Eventual Outcome in the Series of 44 Patients

\begin{tabular}{|c|c|c|c|c|c|c|}
\hline \multirow{2}{*}{\multicolumn{2}{|c|}{ Outcome }} & \multicolumn{2}{|c|}{ Gastric Cooling } & \multicolumn{2}{|c|}{$\begin{array}{l}\text { Conservative } \\
\text { Management }\end{array}$} & \multirow{2}{*}{ Total } \\
\hline & & Under 50 & Over 50 & Under 50 & Over 50 & \\
\hline \multicolumn{2}{|c|}{$\begin{array}{l}\text { Complete recovery.: } \\
\text { Successful operation: } \\
\text { Elective .. }\end{array}$} & & & 6 & 11 & 32 \\
\hline $\begin{array}{l}\text { Elective } \\
\text { Emergency } \\
\text { Death: }\end{array}$ & $\ddot{*}$ & 1 & $\begin{array}{l}1 \\
1\end{array}$ & & 1 & $\begin{array}{l}2 \\
2\end{array}$ \\
\hline $\begin{array}{l}\text { No operation } \\
\text { Operation }\end{array}$ & 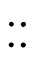 & & $\begin{array}{l}3 \\
1\end{array}$ & & $\begin{array}{l}1 \\
3\end{array}$ & $\begin{array}{l}4 \\
4\end{array}$ \\
\hline Total .. & .. & 6 & 16 & 6 & 16 & 44 \\
\hline
\end{tabular}
TABLE III.-Causes and Times of the 8 Deaths in the Series of 44

Gastric Cooling

A.B.: 64 years, male, cardiac infarction; during G.C.

C.D.: 56 years, male, hepatic failure; one month after G.C.

E.F.: 66 years, female, stroke and cardiac infarction; 12 days after G.C.

Conservative Management

S.T.: 70 years, male, cardiac failure and continuing haemorrhage; four days

W.V.: 58 years, male, hepatic failure; 27 days

W.X.: 78 years, female, post-gastrectomy leak and cardiac infarction; 18 days

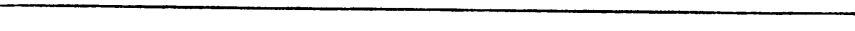

TABLE IV.-Degree of Success or Failure or Arrest of Haemorrhage in 22 Patients Treated with Gastric Cooling

\begin{tabular}{c|c|c|c|c|c|c|c|c}
\hline & \multicolumn{2}{|c|}{ Under 50 Years Old } & \multicolumn{3}{|c|}{ Over 50 Years Old } & \\
\cline { 2 - 7 } Degree of Arrest & G.U. & D.U. & $\begin{array}{c}\text { No } \\
\text { Lesion } \\
\text { on Ba } \\
\text { Meal }\end{array}$ & G.U. & D.U. & $\begin{array}{c}\text { No } \\
\text { Lesion } \\
\text { on Ba } \\
\text { Meal }\end{array}$ & Varices & Total \\
\hline $\begin{array}{c}\text { Permanent } \\
\text { Arrest but delayed } \\
\text { recurrence } \\
\text { Arrest but immed- } \\
\text { iate recurrence.. }\end{array}$ & 1 & 2 & 3 & 8 & 3 & 2 & & 19 \\
\hline $\begin{array}{c}\text { Failure .. } \\
\text { Total.. }\end{array}$ & 1 & 2 & 3 & 9 & 4 & 2 & 1 & 22 \\
\hline
\end{tabular}

TABLE V.-Degree of Success or Failure of Arrest of Haemorrhage in

\begin{tabular}{|c|c|c|c|c|c|c|c|c|c|}
\hline \multirow{2}{*}{\multicolumn{2}{|c|}{ Degree of Arrest }} & \multicolumn{2}{|c|}{$\begin{array}{l}\text { Under } 50 \\
\text { Years Old }\end{array}$} & \multicolumn{5}{|c|}{ Over 50 Years Old } & \multirow[b]{2}{*}{ Total } \\
\hline & & D.U. & $\begin{array}{c}\text { No } \\
\text { Lesion } \\
\text { on Ba } \\
\text { Meal } \\
\end{array}$ & G.U. & D.U. & $\begin{array}{c}\text { No } \\
\text { Lesion } \\
\text { on } \mathrm{Ba} \\
\text { Meal }\end{array}$ & Varices & $\mathrm{Ca}$. & \\
\hline $\begin{array}{l}\text { Permanent } \\
\text { Failure } \quad . \\
\end{array}$ & $\because$ & 4 & 2 & $\begin{array}{l}3 \\
1 \\
\end{array}$ & $\begin{array}{l}3 \\
3 \\
\end{array}$ & $\begin{array}{l}3 \\
1\end{array}$ & 1 & 1 & $\begin{array}{r}15 \\
7\end{array}$ \\
\hline Total.. & $\cdots$ & 4 & 2 & 4 & i & 4 & 1 & 1 & 22 \\
\hline
\end{tabular}

contents, and haemoglobin level) in association with gastric cooling. This is for six patients under 50 years old (all successfully treated) and 16 over 50 years old. There was permanent success in $19(86 \%)$ of the 22 cases.

Table $\mathrm{V}$ indicates the comparable figures for the 22 cases initially treated conservatively. In this group there was permanent arrest of haemorrhage in $15(68 \%)$ of the cases. In both groups failures were limited to patients over 50 years old.

In Fig. 4 it may be seen that the average for the total blood transfused to each patient in the gastric-cooling group is 8.6 units $(540 \mathrm{ml}$. per unit) compared with 8.3 units in the conservatively managed group.

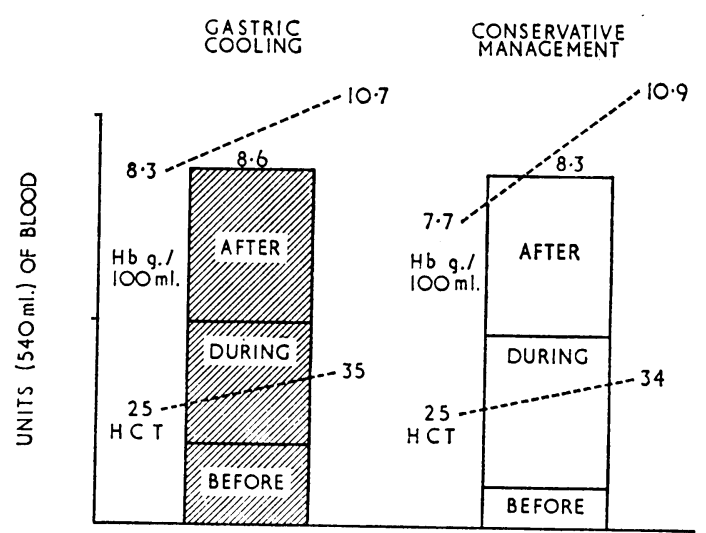

FrG. 4.-Comparison of the average amounts of blood transfused and the haemoglobin and haematocrit levels in the two groups of patients.

\section{Evaluation of the Hypothermia Machine}

The Cryocycle hypothermia system functioned very smoothly throughout the work. The plastic tubing, naturally, underwent some wear, but the second set was still being used at the end of the project. New balloons were used for each treatment; standard high-quality condoms proved ideal.

The most important temperature reading was that of the intragastric probe. If this remained steady and between 20 and $15^{\circ} \mathrm{C}$. it was a good indication that coolant flow was proceeding satisfactorily. The average fall in rectal temperature was a few degrees only (as indicated in Fig. 3). However, it was possible for this to drift lower if external warming were not vigorous.

The hypothermia machine had the great advantage of being designed for gastric cooling only-that is, it was impossible when water was being circulated in the manner described for temperatures to fall below $0^{\circ} \mathrm{C}$. This meant that the only immediate supervision necessary was that ice should be maintained in the bath.

\section{Complications of Gastric Cooling}

No catastrophic complications such as stomach rupture due to overdistension were encountered. This would seems to be almost impossible with the hypothermia machine used in this work.

Though cardiac infarction accounted for two deaths in patients who had gastric cooling this could quite reasonably be regarded as coincidental. Electrocardiography did not show any "injury potential" in association with gastric cooling.

Chest infection was the most common problem. During gastric cooling the intragastric balloon possibly gave some degree of left chest "splintage," though infection was not noticeably more marked on the left side. The patients were relatively immobilized in the supine position, and some inhalation of blood or mucus must have occurred quite often in spite 
of the care taken. In retrospect, moderate inclination of the upper trunk would probably have been wise.

When operations on the stomach were done urgently not long after gastric cooling had been under way there were no untoward findings in the gross or microscopical appearances of the stomach. Nor was there any evidence that postoperative healing was prejudiced by gastric cooling.

\section{Discussion}

In this study gastric cooling was carried out for a 24-hour period in all but a few of the cases so treated. This was because a review of the duration of treatment used by other workers (when they stated this) suggested this to be a reasonable time to control haemorrhage and minimize the chance of its immediate recurrence. It proved satisfactory to adhere to this period as a basis for comparative study, but probably a shorter period could be effective in some cases.

The definition of "massive" haemorrhage in terms of the blood loss, the patient's condition, and haemoglobin and haematocrit levels was arbitrary. It would not allow strict comparison with other reported series, but was a good practical guide for inclusion of patients in this series. Only after the patient had been accepted was the card indicating the method of treatment consulted.

Comparison between the two groups by examination of the "degree of arrest of haemorrhage" (Tables IV and V) would suggest that gastric cooling (three recurrences or failures) had a better success rate than the conservative group (seven failures), but statistical evaluation of these data (Table VI) indicates that any difference in the arrest of haemorrhage is not significant. Moreover, Table II shows that the eventual outcome (four deaths) was the same for each group.

TABLE VI.-Statistical Evaluation of Data from Tables IV and V

\begin{tabular}{|c|c|c|c|c|c|c|}
\hline & & & & $\begin{array}{l}\text { Gastric } \\
\text { Cooling }\end{array}$ & $\begin{array}{l}\text { Conservative } \\
\text { Management }\end{array}$ & Total \\
\hline \multicolumn{2}{|c|}{$\begin{array}{l}\text { Permanent arrest } \\
\text { Degree of cooling }\end{array}$} & $\therefore$ & $\therefore$ & $\begin{array}{r}19 \\
3\end{array}$ & $\begin{array}{r}15 \\
7 \\
\end{array}$ & $\begin{array}{l}34 \\
10 \\
\end{array}$ \\
\hline Total & .. & .. & . & 22 & 22 & 44 \\
\hline
\end{tabular}

In Fig. 4 the volume of blood transfused and the degree of anaemia show some minor differences (the conservative group had marginally lower haemoglobin levels at the start and throughout the period of review; less blood was transfused to those under 50 years-conservative group), but the overall similarity of the figures is striking. In particular an average of 8.6 units of blood was given to the gastric cooling group, while an average of 8.3 units was given to the controls.

It is evident that there is no significant difference between the two groups.

\section{Summary}

In a prospective study gastric cooling was used as an adjunct to initial conservative management of patients with serious upper gastrointestinal haemorrhage.

It has been shown that this method conferred no benefit on this group of patients compared with a similar group managed by expectant measures only.

This relative failure was not due to technical deficiencies; the hypothermia apparatus functioned smoothly and appeared to be superior to most earlier units.

The overall experience with this technique suggested that it may be useful when haemorrhage is persisting and there are strong reasons for avoiding operation.

This work was supported by a grant from the Medical Research Council. The Cryocycle hypothermia system, used throughout, was made available by Edward Weck and Co., Long Island City, New York. We are grateful also to the physicians and surgeons of Sefton General Hospital who referred cases and to Sister E. Edwards and Sister D. Markey for their expert nursing.

REFERENCES

Crampton, R. S., Cali, J. R., Yerys, P., Buetow, G. W., and Glaubitz, J. P. (1964). Surgery, 55, 607.

Miller, R. E., Moscarella, A. A., and Fitzpatrick, H. F. (1963). Arch. Surg., 86, 272.

Nicoloff, D. M., Griffen, W. O., jun., Salmon, P. A., Peter, E. T., and Wangensteen, O. H. (1962). Surg. Gynec. Obstet., 114, 495.

Richman, A., and Anthony, D. (1963). Amer. F. dig. Dis., 8, 113.

Wangensteen, O. H., Root, H. D., Jenson, C. B., Imamoglu, K., and Salmon, P. A. (1958). Surgery, 44, 265.

Wangensteen, S. L. (1962). Surg. Clin. N. Amer., 42, 1171.

Wrahood, R. C., Voorhees, A. B., Smith, R. B., III, and Healey, w. V. (1963). Amer. F. Surg., 105, 401.
Samples of cerebrospinal fluid were obtained from patients in the following groups:

(1) Hospital Controls: The 30 patients in this group were admitted for investigation of neurological or psychiatric symptoms.
However, in no instance was there evidence of active neurological disease. Several patients who had cerebrovascular accidents some months before admission were included in the control group. The C.S.F. was normal in respect of the total protein, cell count, and Pandy, Nonne-Apelt, and Lange tests.

(2) Patients with miscellaneous neurological diseases including: those with epilepsy being treated with anticonvulsants and those with multiple sclerosis and varied tumours of the nervous system.

The C.S.F. was centrifuged and the supernatant taken for analysis. Blood for the serum folate estimation was taken while the patient was fasting. The serum was separated within two hours from the time of venesection. Ascorbic acid (5 $\mathrm{mg} . / \mathrm{ml}$.) was added to the C.S.F. and serum. Specimens were stored at $-20^{\circ} \mathrm{C}$. until analysis.

\footnotetext{
* Formerly Resident Pathologist, the N tional Hospital, Queen Square, London W.C. 1 .

t Department of Haematology, the H.spital for Sick Children, Great Ormond Street, London W C.1.
} 